\title{
SOBRE O PODER GLOBAL'
}

\author{
JOSÉ LUÍS FIORI
}

\section{RESUMO}

$\mathrm{O}$ artigo discute as possibilidades e limites da idéia de uma "governança global". O autor retoma a teoria da estabilidade hegemônica e seu desdobramento no debate em torno das noções de "hegemonia" e "governança" mundiais. Examina então a constituição e expansão de economias e poderes hegemônicos desde o século XVII, a fim de extrair premissas teóricas acerca das condições reais sob as quais pode haver governabilidade global, para além de um ideal cosmopolita kantiano.

PALAVRAS-CHAVE: hegemonia internacional; governança global;

sistema mundial.

\section{SUMMARY}

The article discusses the possibilities of "global governance". Taking the notions of global "hegemony" and "governance" as a guideline, the author examines the constitution and expansion of hegemonic powers since the 17th century. Further on, he puts into question the notion of "cosmopolitanism" proposed by Kant and discusses the actual possibility of a global government.

KEYWORDS: international hegemony; global governance; world system.

\begin{abstract}
"A mera preservação da existência social exige, na livre competição, uma expansão constante. Quemnão sobe, cai. Ea expansão significa o domínio sobre os mais próximos e sua redução ao estado de dependência. [...] o que temosé um mecanismo social muito simples que, uma vez posto em movimento, funciona com a regularidade de um relógio."
\end{abstract}

NORBERT ELIAS, Oprocesso civilizador

[1] Este trabalho foi originalmente escrito para o seminário "Innovation systems and development strategies for the Third Millenium", realizado no Rio de Janeiro de 3 a 5 de novembro de 2003 .

[2] Kindleberger,Charles.The world in depression, 1929-39. Berkeley: University of California Press, 1973, p.304.
Foi no início da década de 1970 que Charles Kindleberger e Robert Gilpin formularam a tese fundamental que mais tarde foi chamada de "teoria da estabilidade hegemônica". O mundo enfrentava as primeiras manifestações da crise internacional que se seguiu ao fim do sistema de Bretton Woods e à derrota dos Estados Unidos no Vietnã, e os dois autores estavam preocupados com a possibilidade de que se repetissem a crise e a Grande Depressão dos anos 1930, por falta de uma liderança mundial. Foi quando Kindleberger afirmou que o bom funcionamento de "uma economia liberal mundial necessita de um estabilizador e de um só país estabilizador"2 - um país que provesse o sistema mundial de alguns "bens públicos" indispensáveis para o seu funcionamento, como uma moeda internacional e o livre-comércio, ou da coordenação das políticas econômicas nacionais e da promoção de políticas anticíclicas de eficácia global.A tese de Kindleberger tinha uma natureza 
claramente normativa, mas se apoiava numa leitura teórica e comparativa da história do sistema capitalista. Como sintetizou Gilpin: "a experiência histórica sugere que, na ausência de uma potência liberal dominante, a cooperação econômica internacional mostrou-se extremamente difícil de ser alcançada ou mantida"3. Kindleberger falou inicialmente de uma "liderança" ou "primazia", mas depois um número cada vez maior de autores passou a utilizar o conceito de "hegemonia mundial". Às vezes com a conotação pura e simples de um poder acima de todos os demais; outras vezes com uma conotação mais "gramsciana", de um poder global legitimado pelos demais Estados, graças à eficácia "convergente" de sua governança mundial.

A tese não era completamente nova, pois já havia sido formulada quase que literalmente por Edward Carr em 1939 no seu clássico ensaio A crise dos vinte anos. Carr era um realista e estava discutindo o problema da manutenção da paz entre Estados soberanos - no momento em que começava a II Guerra Mundial -, mas sua conclusão era muito parecida com a de Kindleberger e Gilpin: "a condição da legislação internacional é o super-Estado"4. Uma tradução para o campo internacional do velho e conhecido argumento hobbesiano: "Antes que se designem o justo e o injusto, deve haver alguma força coercitiva". Alguns anos depois, Raymond Aron praticamente afirmava o mesmo ao dizer que não haveria paz mundial "enquanto a humanidade não tivesse se unido num Estado Universal"5. Aron privilegiava o "império da lei", conforme a visão cosmopolita e liberal de Kant, mas reconhecia a importância da "política de poder", como o próprio Kant, que também dissera no seu devido tempo que "o homem é um animal que, ao viver entre outros da mesma espécie, tem necessidade de um senhor que o obrigue a obedecer a uma vontade universalmente válida". Todos falavam em preservação da paz, e não do bom funcionamento da economia internacional, como Kindleberger e Gilpin, mas todos reconheciam, em última instância, a necessidade de algum tipo de poder político supranacional como condição de uma ordem mundial estável, fosse ela econômica ou política.

Durante a década de 1980, a "teoria da estabilidade hegemônica" foi submetida a uma crítica minuciosa por suas inconsistências teóricas e históricas. Vários autores questionaram a idéia de que Inglaterra houvesse promovido intencionalmente a adesão dos demais países ao padrão-ouro no século XIX, e demonstraram historicamente que na maioria dos casos o comportamento dos países hegemônicos se orientou pelos seus próprios interesses nacionais, por vezes transformandose mais em obstáculo do que em condição da estabilidade internacional ${ }^{6}$. Susan Strange, em particular, mostrou que as crises sistêmicas ao longo da história têm sido causadas muito mais por fatores internos à sociedade e à economia do país hegemônico do que pelo comportamento dos países que usufruem e contestam o sistema7. Nessa mesma linha, Andrew Walter conclui que
[3] Gilpin, Robert. The political economy of the international relations. Princeton:Princeton University Press, 1987, p. 88.

[4] Carr, Edward H. The twenty years crisis, 1919-39. Nova York: Perennial, 2001, p. 211.

[5] Aron, Raymond.Paz eguerra entre as nações. Brasília: Editora Universidade de Brasília, 1962, p. 47.
[6] Cf. McKeown, TimothyJ. “Hegemonic stability theory and 19th century tariff levels in Europe". International Organization, vol. 37, no 1, 1983; Rogowski, Ronald. "Structure, growth and power: three rationalist accounts". International Organization, vol. 37, no 4, 1983; Stein, Arthur. "The hegemon's dilemma: Great Britain, the United States, and the international economic order". International Organization, vol. 38, no 2, 1984; Russet, Bruce. "The mysterious case of vanishing hegemony or, is Mark Twain really dead?". International Organization, vol. 39, no 2, 1985; Snidal, Duncan. "The limits of hegemonic stability theory". International Organization, vol. 39, no 4, 1985. 
[7] Strange, Susan. "The persistent myth of lost hegemony". International Organization, vol. 41, no 41987.

[8] Walter, Andrew. World power and world money. Londres: Harvester Wheatsheaf, 1993, p. 249. a função hegemônica do estabelecimento e da manutenção de regras devia ser vista como de limitado valor descritivo. A distinção entre os papéis da imposição de regras, do estímulo à coordenação política entre os Estados e da gestão e de uma cautelosa supervisão do sistema monetário e financeiro internacional nos habilitava a entender melhor as diferentes pretensões à hegemonia que haviam se apresentado ${ }^{8}$.

Por outro lado, a história das últimas décadas do século XX também contradisse a teoria da estabilidade hegemônica. Nestes últimos trinta anos, em particular após a segunda metade dos anos 1980, o mundo esteve sob a "liderança" incontestável de uma só potência, orientada por um forte commitment liberal. Como propunha Kindleberger, durante esse período os Estados Unidos arbitraram isoladamente o sistema monetário internacional, promoveram ativamente a abertura e a desregulação das economias nacionais e o livre-comércio, incentivaram a convergência das políticas macroeconômicas e atuaram - pelo menos em parte como last resort lender em todas as crises financeiras que abalaram o mundo dos negócios, mantendo, ao mesmo tempo, um poder incontrastável nos planos industrial, tecnológico, militar, financeiro e cultural. Apesar de tudo isso, o mundo viveu nesse período uma conjuntura de grande instabilidade sistêmica, tanto no campo financeiro como no das relações político-militares.

A despeito das críticas teóricas e das inconsistências históricas, a preocupação inicial de Kindleberger e Gilpin tornou-se o denominador comum de uma extensa literatura - sobretudo nos Estados Unidos acerca da "crise da hegemonia norte-americana". E sua tese comum a respeito da necessidade mundial de "países estabilizadores" ou "hegemônicos" transformou-se no foco de um longo debate acadêmico sobre o conceito e as funções das "hegemonias mundiais", que algum tempo depois se prolongou na discussão sobre o que se convencionou chamar de "governança global".

De um lado se alinharam, desde o início, os "realistas" ou "neo-realistas" de variados matizes, aprofundando a discussão sobre a origeme o poder dos Estados hegemônicos e sobre as formas de sua "gestão global", baseadas na sua capacidade material e no seu controle sobre as matérias-primas estratégicas, os capitais de investimento, as tecnologias de ponta, as armas e as informações. Kindleberger e Gilpin pertenciam a esse grupo, inaugurado por Edward Carr. Mas aí também se incluíam os "estruturalistas", como Susan Strange, que criticavam a teoria da estabilidade hegemônica mas reconheciam a existência de "poderes estruturais globais", controlados por sucessivas potências dominantes e capazes de induzir comportamentos coletivos sem necessidade do uso da força. Da mesma forma, um grupo de autores marxistas ou neomarxistas, como Immanuel Wallerstein e Giovanni Arrighi, partia do conceito e da história do "modern world system" para concluir que ao longo dos últimos quinhentos anos a competição entre 
os Estados nacionais europeus só não degenerou em caos político e econômico graças ao comando de três grandes potências hegemônicas capazes de organizar ou "governar" o funcionamento hierárquico do sistema mundial criado na Europa durante o século XVI — algo como "ciclos hegemônicos" comandados sucessivamente pelos Países Baixos, no século XVII, pela Grã-Bretanha, no século XIX, e pelos Estados Unidos, no século XX9. Mais recentemente, Antonio Negri e Michael Hardt introduziram no campo marxista a tese de que o mundo já estaria sendo governado por uma nova forma de "império" pós-nacional, uma espécie original de "supra-estrutura política" correspondente a uma economia mundial que já teria sido globalizada pela ação desnacionalizante do "capital"10.

Numa posição oposta à dos realistas colocaram-se, desde a primeira hora, os "liberais" ou "pluralistas", como Joseph Nye e Robert Keohane, os verdadeiros pais da idéia de "governança global". Estavam convencidos - como Negri e Hardt, muito mais tarde - da perda de importância dos Estados nacionais e da possibilidade de criação de uma nova ordem política e econômica mundial, estabilizada e gerida com base em "regimes supranacionais" legítimos, capazes de funcionar com eficácia mesmo na ausência de potências hegemônicas. Segundo Keohane e Nye, verdadeiras "tramas de regras, normas e procedimentos que regularizariam comportamentos e controlariam efeitos [...] e que, uma vez estabelecidas, seriam difíceis de erradicar ou rearranjar". Mas mesmo eles reconheciam a existência de situações "em que não há normas e procedimentos consensuais ou em que as exceções às regras são mais importantes que os casos de aderência" ${ }^{11}$. Nessas circunstâncias, a hierarquia e o poder dos Estados permaneceriam decisivos para a definição dos regimes e das soluções impostas à comunidade internacional. Uma qualificação necessária, mas que reabre o problema da coordenação ou governança de um sistema que segue sendo interestatal. Raymond Aron tentou resolver essa dificuldade propondo uma distinção entre dois tipos de subsistemas internacionais que coexistiriam lado a lado: um mais "homogêneo" e o outro mais "heterogêneo", dependendo do grau em que os Estados envolvidos compartilhassem ou não concepções e valores internacionais. Mas Aron não consegue explicar por que as grandes divergências e guerras quase sempre se deram no âmbito dos sistemas "homogêneos", o que reforça a tese realista de que não haveria possibilidade de governança mundial sem uma clara definição da supremacia entre as grandes potências.

Resumindo, não há dúvida de que a teoria da estabilidade hegemônica não resiste à prova da história e de que os conceitos de "hegemonia" e "ciclos hegemônicos" parecem excessivamente associados a uma visão funcionalista do "sistema mundial". Como se o "hegemon" fosse um "ente virtual" mais do que real, uma espécie de exigência funcional do sistema político criado pela Paz de Vestfália e do sistema econômico criado pela expansão e globalização das economias
[9] Wallerstein, Immanuel. The modern world system. Nova York: Academic Press, 1974; Arrighi, Giovanni. "A crisis of hegemony". In:Amim, Samir e outros. Dynamics of global crisis. Londres: The MacMillan Press, 1982. Ver também Arrighi, Giovanni. $O$ longo século XX. Rio de Janeiro/São Paulo: Contraponto/Unesp, 1994.

[10]Hardt, Michael e Negri, Antonio. Império. Rio de Janeiro: Record, 2001.

[11] Keohane, Robert e Nye, Joseph. Power and Interdependence: world politics in transition. Boston: Little Brown, 1977, pp. 19, 55 e 20. 
[12] Braudel, Fernand. A dinâmica do capitalismo. Rio de Janeiro: Rocco, 1987, pp. 85 e 82. nacionais européias: a exigência funcional de um "poder estabilizador" da economia e de um "poder pacificador" das relações entre os Estados soberanos.

Mas quais foram, ao longo da história, esses poderes ou gestores globais? Como foi que eles definiram as normas e regras próprias dos "regimes de governança mundial"? Que relação haveria entre esses poderes e o processo de globalização dos mercados e da economia capitalista? São perguntas que permanecem sem respostas a menos que se faça uma reconstituição analítica cuidadosa do processo de organização dos primeiros Estados e economias nacionais capazes de se expandir para fora de si mesmos e impor sua liderança ou hegemonia sobre os demais Estados do sistema mundial.

\section{ORIGEM E EXPANSÃO DO PODER E DA ECONOMIA GLOBAIS}

Ao estudar a formação dos primeiros "mercados nacionais" europeus, no terceiro volume de Civilização material, economia e capitalismo dos séculos XV-XVIII, Fernand Braudel defende a tese de que

a economia nacionalé um espaço político que foi transformado pelo Estado, em virtude das necessidades e inovações da vida material, num espaço econômico coerente, unificado, cujas atividades passaram a se desenvolver em conjunto numa mesma direção.

E conclui que "só a Inglaterra realizou essa façanha precocemente", mediante "a revolução que criou o mercado nacional inglês" 12 . O essencial nesse ponto é que Braudel afirma que os primeiros mercados e economias nacionais, que nasceram na Europa, não foram uma obra espontânea ou expansiva da divisão do trabalho provocada pela tendência dos indivíduos à troca de mercadorias: foram uma obra do poder e uma estratégia política do Estado, que recortou e extraiu o novo "espaço econômico" de um conjunto mais amplo e preexistente, que Braudel chamou de "economia-mundo européia". Karl Marx descreve esse mesmo momento do nascimento da economia nacional inglesa no Capítulo XXIV do Capital, em que trata do processo da acumulação originária:

As diversas etapas da acumulação originária tiveram seu centro, por ordem cronológica mais ou menos precisa, na Espanha, Portugal, Holanda, França e Inglaterra. Mas foi na Inglaterra, em fins do século XVII, que esse processo se resumiu e sintetizou sistematicamente no "sistema colonial", no "sistema da divida pública", no "moderno sistema tributário" e no "sistema protecionista". Em grande medida, todos esses métodos se baseiam na mais avassaladora das forças. Todos eles se valem do poder do Estado.

Nesse novo contexto econômico nacional, diz Marx, 
a divida pública se converte numa das mais poderosas alavancas da acumulação originária. Funciona como uma varinha mágica que infunde virtude procriadora ao dinheiro improdutivo e o converte em capital sem expô-lo aos ris$\cos [\ldots]$, como se fosse um capital chovido do céu $u^{13}$.

A relação entre o Poder o o Dinheiro, ou entre príncipes e banqueiros, é muito antiga e remonta às cidades do Norte da Itália, onde nasce o sistema bancário moderno, ligado ao comércio de longa distância è administração das dívidas do Vaticano. Daí vêm os primeiros empréstimos para as guerras travadas pelos donos do poder, como Eduardo II da Inglaterra, que no século XIV se endividou com a banca de Siena para financiar a tomada do País de Gales. Saiu vitorioso da guerra mas não pagou sua dívida, o que levou o sistema bancário de Siena à falência e transferiu para Florença a hegemonia financeira da Itália. Isso se repetiu muitas vezes, como na relação de Carlos $\mathrm{V}$ com os banqueiros alemães que financiaram a contínua expansão de suas guerras e territórios, até o momento em que ele decretou a moratória de 1557, responsável pela falência da Casa dos Fugger.

Mas o que Marx descreve no século XVII é uma relação absolutamente diferente entre o poder e o dinheiro, que só foi possível depois da "revolução econômica" de que fala Braudel. Uma vez que a Inglaterra virou uma ilha e constituiu sua economia nacional, a relação entre os governantes e os banqueiros mudou de natureza. Nessa nova realidade não mais se tratava de uma relação e de um endividamento pessoais do príncipe com uma casa bancária de qualquer nacionalidade: a relação de endividamento se dava entre o Estado e os bancos de uma mesma unidade territorial ou de uma mesma economia nacional. A dívida pública tornou-se portanto interna, administrada por algum tipo precursor de Banco Central, e pôde se transformar na base do sistema bancário e de crédito da Inglaterra.

Como conseqüência, nasce um "interesse nacional" inglês que é simultaneamente econômico e político, e essa unidade se transforma numa força propulsora gigantesca e sem equivalente na história passada da acumulação do poder e da riqueza, uma força que ultrapassará as fronteiras nacionais da Inglaterra. Trata-se de um verdadeiro salto qualitativo na história do poder, do dinheiro e do sistema mundial. Inicia-se então a escalada do poder nacional inglês na direção do poder global ou da hegemonia mundial.Eessa expansãoé que criará as bases "materiais" de uma nova "economia mundial", diferente da "economia-mundo" de que fala Braudel, que ainda era organizada em torno das grandes cidades mercantis da Itália e do Norte da Europa.

Na hora dessa revolução, no entanto, a Inglaterra não estava só. Pelo contrário, já existiam um "sistema político" e uma rede de Estados europeus que vinham se consolidando desde o século XIV mediante uma sucessão quase infinita de conflitos que culminaram na Guerra dos 30 Anos (1618-48), o verdadeiro berço das soberanias nacionais. Foi a Paz
[13] Marx, Karl. El Capital. México: Fondo de Cultura Económica, 1980, pp. 638 e 685 . 
de Vestfália, assinada em 1648, que consagrou o princípio da "soberania nacional" e gerou o "sistema político-estatal europeu". Mas ao consagrar o princípio da soberania criou um sistema de poder anárquico, no qual o exercício do "equilíbrio de poder" e a guerra se tornaram as duas formas conhecidas e possíveis de resolução dos conflitos entre os Estados soberanos. Configurou-se, assim, uma forma primitiva de governança supranacional.

Portanto, o novo sistema estatal nasceu competitivo e movido pela possibilidade permanente da guerra. É nesse contexto que se deve compreender a radicalização do mercantilismo inglês praticado por Cromwell logo depois da revolução de 1648. Naquele momento, criar uma economia nacional consistiu sobretudo numa estratégia de guerra de um país inferiorizado frente ao poder econômico holandês e ao poder militar de Luís XIV. A partir daí, e da explosão do poder inglês, todos os demais Estados europeus tentaram repetir a mesma estratégia, de modo que se multiplicou o número das economias nacionais, mas sem o mesmo sucesso dos ingleses.

Em síntese, as primeiras "economias nacionais" nasceram como uma estratégia de guerra defensiva dos primeiros Estados territoriais europeus e depois se transformaram numa imposição do sistema político interestatal, cuja regra número umera a continuidadee a intensificação permanente da competição político-militarentre seus Estados-membros.Como resultado, desde o início o sistema político europeu esteve sob o controle compartido ou competitivo de uns poucos Estados que impuseram aos demais sua liderança político-militar e econômica. Foram as grandes potências, que nunca passaram de seis ou sete, que desde o início se transformaram no núcleo dominante de todo o sistema. Na entrada do século XVIII, depois da decadência de Portugal,Espanha, Suécia e Polônia, esse pequeno clube ficou restrito a França, Holanda, Inglaterra, Rússia,Áustria e Prússia, delimitados em conjunto por suas fronteiras militarizadas com o Império Otomano. Mas mesmoentreesses países já existia uma hierarquia, na qual a França de Luís XIV se destacava ao lado da Holanda e da Inglaterra. Em 1748 Frederico II da Prússia dizia, sem nenhum tipo de dúvida, que "a Inglaterra e a França eram os poderes que determinavam o que acontecia na Europa". Por outro lado, a mobilidade dentro desse sistema sempre foi muito lenta e as "barreiras à entrada" de novos "sócios" criadas pelas potências ganhadoras sempre muito altas.

Nesse ponto da história põe-se uma questão teórica decisiva para a discussão do problema da "governabilidade mundial": por que surge e se mantém, ao longo da história desse tipo de sistema político, a vontade imperial de expansão - dos Estadoseeconomias nacionais - queestá na origem de todas as guerras? O sociólogo norte-americano Charles Tilly, um dos maiores pesquisadores da origem do sistema estatal, responde:

Os europeus seguiram uma lógica padronizada de provocação da guerra: todo aquele que controlava meios substanciais de coerção tentava garantir uma 
área segura dentro da qual poderia desfrutar dos lucros da coerção e mais uma zona-tampão fortificada, para proteger a área segura. Quando as potências adjacentes estavam perseguindo a mesma lógica, o resultado era a guerra ${ }^{14}$.

Mas Tilly não explica por que os príncipes e Estados sentem a necessidade inicial de criação de suas primeiras "zonas de segurança". Ele afirma que a guerraéuma conseqüência inevitável do processo de expansão territorial dos Estados, mas tampouco explica a razão da própria expansão. Apesar disso, não é difícil entender que a criação das "zonastampão" responde a uma necessidadee a um sentimento defensivo eque a guerra não é uma conseqüência da expansão territorial dos Estados, como pensa Tilly, mas a sua principal causa. A guerra não está no fim do processo de expansão territorial: está na sua própria origem e acaba se transformando na sua primeira causa ou primeiro motor.

Norbert Elias expõe essa tese de forma extremamente clara no seu Processo civilizador, como vimos na epígrafe deste texto. Em síntese, toda grande potência estará sempre obrigada a seguir expandindo o seu poder, mesmo em períodos de paz. Em primeiro lugar porque a guerra é uma possibilidade constante e inevitável das relações entre as grandes potências; em segundo lugar porque ela só pode ser protelada pela conquista ou acumulação de mais poder; e em terceiro lugar porque nesse sistema, como sentenciou Elias, "quem não sobe, cai"15.

Resumindo nosso ponto de vista, o sistema político e econômico mundial não foi produto de uma simples e progressiva somatória de territórios, mercados, países e regiões. Historicamente, foi uma criação do poder: do poder expansivo e conquistador de alguns Estados/economias nacionais europeus que durante o século XVII se transformaram no pequeno grupo das grandes potências. Até o século XIX o sistema mundial se restringia quase que exclusivamente aos Estados europeus, aos quais se agregaram, no séculoXIX, os novos Estados independentes americanos. Mas foi só na primeira metade do século XX que o sistema incorporou no seu núcleo central duas potências "expansivas" extra-européias, os Estados Unidos eo Japão, um pouco antes que o Estado nacional se generalizasse, já na segunda metade do século XX, como a forma dominante de organização do poder político territorial através do mundo.

Além disso, do nosso ponto de vista, o sistema mundial não existiria na sua forma atual caso não tivesse ocorrido na Europa um casamento entre os Estados e as economias nacionais. E a partir desse momento o que muitas vezes se chama de "globalização" é o processo e o resultado de uma competição secular entre esses Estados/economias nacionais. A hierarquia, a competição e a guerra dentro do núcleo central do sistema mundial marcaram o ritmo e a tendência do conjunto na direção de um império ou Estado universal e de uma economia global. Mas esse movimento não tem nada a ver com o avanço de uma espécie de "razão hegeliana" de natureza global e convergente. Ao contrário, é um movimento que avança sempre liderado por algum Estado/economia nacional em
[14] Tilly, Charles. Coerção, capital e Estados europeus. São Paulo: Unesp, 1993, p. 127

[15] Elias, Norbert. O processo civilizador. Rio de Janeiro: Jorge Zahar Editor, 1976, vol. 2 . 
particular. Por isso mesmo nunca se completa, já que sempre acaba se deparando com a resistência das demais "vocações imperiais" do sistema. Os ganhadores transitórios dessa competição sempre foram os que conseguiram chegar mais longe e garantir de forma mais permanente o controle de "territórios políticos eeconômicos" supranacionais, mantidos na forma de colônias, domínios ou periferias independentes, mas pouco soberanas. Contudo, só duas das grandes potências lograram impor o seu poder e expandir as fronteiras de suas economias nacionais até quase o limite da constituição de um império mundial: a Inglaterra e os Estados Unidos. Esse processo deu um passo enorme depois da generalização do padrão-ouro e da desregulação financeira promovida pela Inglaterra na década de 1870. E deu outro passo gigantesco depois da generalização do padrão "dólar flexível" e da desregulação financeira promovida pelos Estados Unidos a partir da década de 1970.

POSSIBILIDADES E LIMITES DE UMA "GOVERNANÇA MUNDIAL”

Para discutir as possibilidades reais de "governança" desse sistema mundial que estamos examinando, é necessário partir das premissas teóricas acima apresentadas para poder analisar melhor a experiência histórica conhecida. Como vimos, trata-se de um sistema movido por duas forças político-econômicas contraditórias. Por um lado atua a tendência na direção de um império ou Estado universal, que não tem nada a ver com o sonho federativo e cosmopolita de Kant: seria sempre um império imposto por um Estado aos demais Estados nacionais. E nesse caso o projeto da "governança coletiva" teria de enfrentar o problema de que "os impérios não têm interesse em operar dentro de um sistema internacional; eles aspiram a ser o próprio sistema internacional" ${ }^{16}$. Por outro lado, porém, o sistema mundial sempre contou com uma contratendência aos projetos imperiais que aponta na direção da anarquia criada pela Paz de Vestfália e de sua recusa a qualquer tipo de poder superior às soberanias nacionais. Mas a experiência histórica ensina que se não houve império mundial tampouco houve caos, porque o sistema se hierarquizou e criou, na prática, várias formas individuais ou coletivas de gestão supranacional da paz, da guerra e da economia. Formas de gestão imperfeitas e transitórias, quase sempre atropeladas e destruídas por novos impulsos da tendência imperial.

É no âmbito dessa dinâmica contraditória do sistema mundial que se deve pensar o que foi, ou possa ser, uma situação de hegemonia e de governabilidade globais. Um hegemon não pode ser nem nunca será apenas um gerente funcional, nem tampouco uma forma ou função institucional que possa ser ocupada por qualquer tipo de governante coletivo. Ao contrário, a hegemonia mundial foi e sempre será uma posição de poder disputada e transitória, e nunca será o resultado de um consenso ou de uma eleição democrática. A posição hegemônica, portanto é uma conquista, uma vitória do Estado mais poderoso num determinado 
momento, e nesse sentido é ao mesmo tempo um "ponto" na curva ascendente desse Estado rumo ao império mundial. É um típico ponto de passagem, um momento de negociação ou um movimento tático imposto pela estratégia ascensional dos candidatos ao império global. Mas foi quando ocuparam essa posição transitória que os países hegemônicos puderam exercer as funções de um governo global, mais ou menos favoráveis ao desenvolvimento econômico e político dos demais membros do sistema.

Por outro lado, na história do sistema mundial só houve hegemonia de fato quando ocorreu coincidência ou convergência dos interesses e valores da potência ascendente com os das demais grandes potências transitoriamente derrotadas ou superadas pela escalada imperial dos dois únicos grandes vitoriosos dessa história: a Inglaterra e os Estados Unidos. Só nos momentos excepcionais em que se deu essa convergência é que se pode ao mesmo tempo falar de hegemonia e pensar na possibilidade da existência eficaz de regimes internacionais capazes de sustentar ou regular algum tipo de governança mundial. Assim, só se pode falar de uma verdadeira hegemonia mundial em dois momentos da história do sistema moderno:entre 1870 e 1900 e entre 1945 e 1973. E foi só nesses momentos de convergência e harmonia de interesses que eventualmente existiram "regimes internacionais" e instituições multilaterais eficazes. Fora dessas circunstâncias - na ausência de harmonia e convergência de interesses entre as grandes potências - a "governança mundial" suporia a existência de um único sistema político, em que as divergências pudessem ser resolvidas democraticamente. Mas no sistema mundial em que vivemos a única possibilidade de existência de uma jurisdição política unificada seria sob a égide de um império global, queé, por definição, o oposto de um sistema internacional.

Mesmo assim, a cooperação mantida entre as grandes potências nesses dois únicos períodos hegemônicos da história baseou-se em situações objetivas, regras e instituições completamente diferentes. No caso da hegemonia inglesa não existiram regimes nem instituições multilaterais ou supranacionais, e a cooperação resultou das próprias características da Inglaterra, que tinha uma economia extremamente aberta e dependente do seu comércio externo. E a própria estabilidade da libra sempre dependeu dos superávits obtidos pela economia colonial da Índia e da cooperação dos bancos centrais da França e Alemanha. O sistema monetário internacional baseado na moeda inglesa não foi objeto de nenhum tipo de acordo ou regime monetário pactuado entre as grandes potências. Ao contrário, foi um sistema que nasceu da adesão progressiva dos demais Estados/economias europeus, obrigados a utilizar a libra nas suas novas investidas comerciais e imperiais sobre um mundo que já era "território econômico" inglês. Foi um período em que a coordenação mundial da Inglaterra foi feita sem regimes ou instituições multilaterais, apenas com o uso dos "poderes estruturais" de que dispunha a Inglaterra e de que fala Susan Strange ${ }^{17}$. 
Em toda a história do "sistema mundial moderno", o único período em que foi tentado o exercício de uma "governança global", com base num sistema de regimes e instituições supranacionais, foi entre 1945 e 1973 , durante a hegemonia dos Estados Unidos, conquistada com a vitória na II Guerra Mundial. Mas ainda assim é preciso lembrar que vários desses regimes e instituições concebidos na primeira hora da vitória militar jamais se concretizaram, como no caso da Organização Mundial do Comércio e da própria implementação de alguns dos acordos de Bretton Woods. Na verdade, a economia norte-americana sempre foi fechada, ao contrário da inglesa; só na segunda metade do século XX é que ela acelerou seu processo de globalização, na hora em que os Estados Unidos exerceram seu poder político para organizar uma "ordem mundial", na qual a cooperação e a convergência entre os principais países capitalistas se deveram muito mais à ameaça da Guerra Fria e ao medo da mobilização das grandes massas insatisfeitas, dentro e fora da Europa, do que à opção por um regime democrático de "governança internacional".

A partir dos anos 1980 os Estados Unidos abandonaram o sistema monetário internacional pactuado em Bretton Woods, e o fim desse "regime monetário" não levou o sistema a nenhuma crise terminal. Pelo contrário, destravou a vocação imperial dos Estados Unidos, que desde então acumulam contínuos ganhos de poder com o novo sistema monetário "dólar flexível". E com o desaparecimento do "regime geopolítico bipolar" em 1991 desapareceu também a baseético-ideológica em que se fundara a cooperação entre as grandes potências capitalistas. A década de 1990 talvez tenha sido o momento da história em que o sistema mundial chegou mais perto do seu limite imperial, dos pontos de vista político, econômico e ideológico. Mas desde 2000 estamos assistindo à rapidíssima reversão desse processo e à volta da outra tendência do sistema: a tendência à anarquia. O que parecia ter sido a vitória final do liberalismo anglo-saxão foi cedendo lugar, uma vez mais, à defesa dos interesses nacionais e das zonas de influência de cada uma das grandes potências. O que parecia ter sido uma vitória quase religiosa do liberalismo foi, de fato, o fim de uma era "quase religiosa" e a volta ao mundo nu e cru das soberanias e dos interesses nacionais. Por outro lado, desde a década de 1980, mas em particular nos anos de 1990, desapareceu completamente a convergência de interesses econômicos entre as grandes potências. Nesse período a economia norte-americana cresceu de forma quase contínua, enquanto as economias das demais potências estagnaram e a possibilidade de mobilidade da periferia dentro do sistema ficou praticamente reduzida aos casos da Índia e da China, dois países que questionam potencialmente a liderança norte-americana.

Sob todos os pontos de vista, o mundo nunca esteve tão longe de qualquer coisa que se possa chamar de hegemonia ou ordem mundial.A potência imperial do momento defende há duas décadas a desregulação de todos os mercados e sistemas de comunicação, energia e transportes. Evem abandonando sucessivamente todos os acordos, compromissose 
regimes internacionais que afetem sua capacidade de ação unilateral. Sua moeda agora é rigorosamente universal e não obedece a nenhum regime, apenas às decisões soberanas do FED. Sua economia nacional conquistou espaços fundamentais na direção da globalização da sua moeda, dívida e sistema de tributação. Mas ao mesmo tempo estilhaçouse o apoio à sua liderança moral-internacional, e cada uma das grandes potências se dedica hoje a "recolher os cacos" e a redefinir seus interesses e espaços de influência, de costas para os Estados Unidos.

Nesse cenário internacional, a idéia ou projeto de uma "governança mundial" mantém a beleza ética kantiana e segue sendo uma bandeira ou utopia política válida, mas não é uma realidade provável. Sua existência, quase impossível neste momento, não pode servir de base para nenhum tipo de cálculo estratégico durante a próxima década — talvez durante as próximas. A menos que seja o caso da governabilidade mundial preconizada pelos conservadores, como Nial Ferguson, professor de Harvard e um dos mais festejados historiadores britânicos contemporâneos:

Em vez de se retrair como um caramujo dentro de uma concha eletrônica, os Estados Unidos deveriam se devotar a uma participação mais ampla. Assim como o livre-comércio, isso não ocorre naturalmente, mas requersólidos alicerces institucionais de lei e ordem. Opapel que cabe aos Estados Unidos como um império é estabeleceressas instituições onde elas não existam, se necessáriocomo na Alemanha e no Japão em 1945 - com uso de força militar ${ }^{18}$.

A mesma utopia e o mesmo projeto "liberal" dos fisiocratas franceses do século XVII, que também achavam que o bom funcionamento de uma economia de mercado requereria uma "governança tirânica" que eliminasse os conflitos da vida política. Mas de preferência um tirano que fosse economista, liberal e fisiocrata.

JOSÉ LUÍS FIORI é cientista político e professor titular do Instituto de Economia da UFRJ.
[18] Ferguson, Nial. The cash nexus. Londres: Penguin Books, 2001, p. 416.

Recebido para publicação em 2 de setembro de 2005. NOVOS ESTUDOS CEBRAP 73, novembro 2005 pp. $61-72$ 